\title{
Implementing Emergency Power Supply for Lighting and Sound System for a Mosque based on light and Movement Sensors
}

\author{
Agus Ulinuha ${ }^{1 *}$, Rizky Dian Wicaksana ${ }^{2}$ \\ ${ }^{1}$ Department of Electrical Engineering, Universitas Muhammadiyah Surakarta, Sukoharjo, Indonesia \\ ${ }^{2}$ Department of Electrical Engineering, Universitas Muhammadiyah Surakarta, Sukoharjo, Indonesia \\ * Corresponding author: Agus.Ulinuha@ums.ac.id
}

\section{ARTICLE INFO}

Article history

Received May 2, 2020

Revised May 26, 2020

Accepted May 26, 2020

Available Online May 31, 2020

Keywords

Emergency Power Supply

Solar Photovoltaic

Automatic Transfer Switch

\begin{abstract}
Emergency power supply is necessary for a mosque particularly when prayer is happening while power cuts. The important devices required to remain alive at this event are lighting and sound system. For this purpose, a battery is need to supply the devices, and the lighting and movement sensors that used to control emergency power supply. The battery is powered by a solar photovoltaic (PV) panel. The power supply switching between main power and battery is regulated by Automatic Transfer Switch. A 20 Ah, 12 Volt battery supplied by 50 WP solar PV panel is used to back up the power for $6 \mathrm{~W}$ LED light and sound system. The system is implemented on the Mosque of AlBakri, Mojosongo, City of Surakarta. Research purpose of implementing this system is to solve the problem of power cuts during worship. This research used survey and measurements methods. In conclusion of the implementing this system the prayer may continue even the electricity went out.
\end{abstract}

This is an open access article under the CC-BY-SA license.

\section{Introduction}

Indonesia is the country with majority of people following Islamic Religion. Islam obligates the people performing prayer (shalah) five times a day. It is also strongly recommended that prayer is performed in mosque or mushalah. According to some Islamic guidance additional reward is granted up to 27-time more for those doing prayer together (jama'ah) in mosque. Therefore, some Islamic persons normally get motivated to do prayer in mosque. The mosque is currently equipped with some facilities and, even in some places, the mosque is beautifully built with complete and luxury facilities. Beside requiring some care, the mosque also needs electricity for operation of devices in the mosque.

The important devices required in the mosque are lighting and sound system. Lighting is necessary to make the room bright therefore making the prayer more comfortable. 
While the sound system is required to enable voice of Imam (leader of prayer) may reach the last lap of people joining the prayer. The number of people willing to join prayer together is currently increasing and the present of high-quality sound system is necessary. For some reason, the electricity supplying these devices is momentarily unavailable. If this happens while the prayer is going on, then it may make the prayer unmanageable. It is necessary to have an emergency power supply for these vital devices to immediately replace the supply so that the prayer may still be performed completely.

This paper presents a scheme of emergency power supply that enables immediate replacement of power for lighting and sound system when the electricity from the grid is suddenly unavailable [1]. An equipment consisting of power generator, power storage, power converter, controller and switching devices are developed. This developed equipment will generate power and save it in a battery. When the electricity from the grid is suddenly went out, then the sensors will detect if the prayer is taking place. If no one is in the mosque, meaning that prayer is not taking place, then the system will not provide power for the light and the sound. But, if the prayer is going on in the night, then the system will provide both lighting and sound system. If the prayer is going on at the daylight and the electricity went out, then the system will only supply the sound system.

Since the power saved in the battery is in the form of DC Voltage, and the power required by lighting and sound system is in the form of AC Voltage, an inverter is required to convert DC voltage from battery to supply the lighting and sound system. The transfer of power supply from electricity grid to the emergency power supply is carried out using Automatic Transfer Switch (ATS) that enables fast power replacement [2]-[4]. This will make the situation of prayer calm and people performing prayer can still concentrate on their prayer. When the electricity from the grid is again available, the ATS will quickly switch the power source back to the grid [5]. The equipment and how it works will be described in the following sections.

Power is generated by solar photovoltaic by converting sunlight to electricity. Depending on the light intensity, the solar photovoltaic generates the power accordingly. This type of power generator is absolutely clean and does not requires operational cost. The investment cost is the problem of this power generator, yet its long lifetime that may be up to 25 years will compensate the shortcoming. Another drawback of this power generator is the dependence on sunlight availability causing it cannot generate power in the night or in the cloudy situation [6]. Therefore, the power generated by solar photovoltaic needs to be saved in the storage (battery) that may be used whenever necessary.

Beside the sunlight is sometime unavailable, the light intensity is not always constant. This implies that the voltage generated by solar PV not constant. Therefore, the voltage should be regulated such that, it is sufficient to enable power flowing to the storage [7]. It should be noted that power can only be saved to the battery if the voltage reaches minimum level. For this purpose, a Solar Charger Controller (SCC) is employed to custom the voltage allowing power flowing to the battery. This device also works to check the battery capacity in comparison with the power saved. If the capacity of battery has been fully occupied, then it will discontinue charging. Continue supplying power to the fully charged battery may lead to destructive effects in terms of thermal, electrical and mechanical [4], [8], [9].

The saved power will be used for supplying power for lighting and sound system. An inverter is required for converting DC power from battery into customized AC power for lighting and sound system [10]. 
It is not only converting DC to AC power, but also regulating the voltage and current assuring that the requirements of sound system is satisfied [11]. The sound system is about expensive device where supplying it with constant voltage will present excellence sound and giving long lifetime. Therefore, the power supplied to the device should meet the requirement [12]. For lighting loads, it is not quite necessary to have a very precision power. The lighting system may still work with power slightly different with the requirement even with a bit lower quality. However, since the lighting and sound system are supplied through the same inverter, the power going to lighting system will have the same quality with that going to sound system. The operation of inverter is controlled by ATS determining when the inverter should supply the power for lighting and system.

Automatic Transfer Switch (ATS) is the equipment responsible for replacing the source from electricity grid to battery. If the electricity went out, this equipment detects this problem followed by checking if there is any person in the mosque. If there is person in the mosque, meaning that a prayer is taking place, then a command is given to the inverter to convert DC power from battery to supply sound system. If prayer is performed at the night where the dark situation is detected, then the lighting system will also be supplied. Otherwise, only sound system that only be supplied. The transfer of power source should be quick enough to assure people together doing prayer will not be bothered and they may still focus on their prayer [13]. Once the electricity from the grid is again available then ATS will switch back the source to the grid.

Battery is one of the system components saving the power generated by solar PV. The saved energy in battery will be discharged to supply the load based on the command from ATS. Therefore, the battery proceeds the cycle of charging and discharging, which includes some electrochemical reversible conversion process. This cycle may achieve some number depending on the battery quality [14]. However, for the time being the performance of battery will get lower and after some time this will be very low that may not sufficiently keep the power. If this stage is achieved, then the battery replacement is necessary [15].

The abovementioned description of the proposed system is schematically given in Fig.1. indicating how every component is interconnected. This system has been implemented on the Mosque of Al-Bakri, Mojosongo, City of Surakarta and has performed normally. Some simulation emulating the electricity shut down has been tested. Different conditions have also been simulated including the presence of people and the light intensity representing night or daylight. It was also observed that the system has proportionally respond the situation.
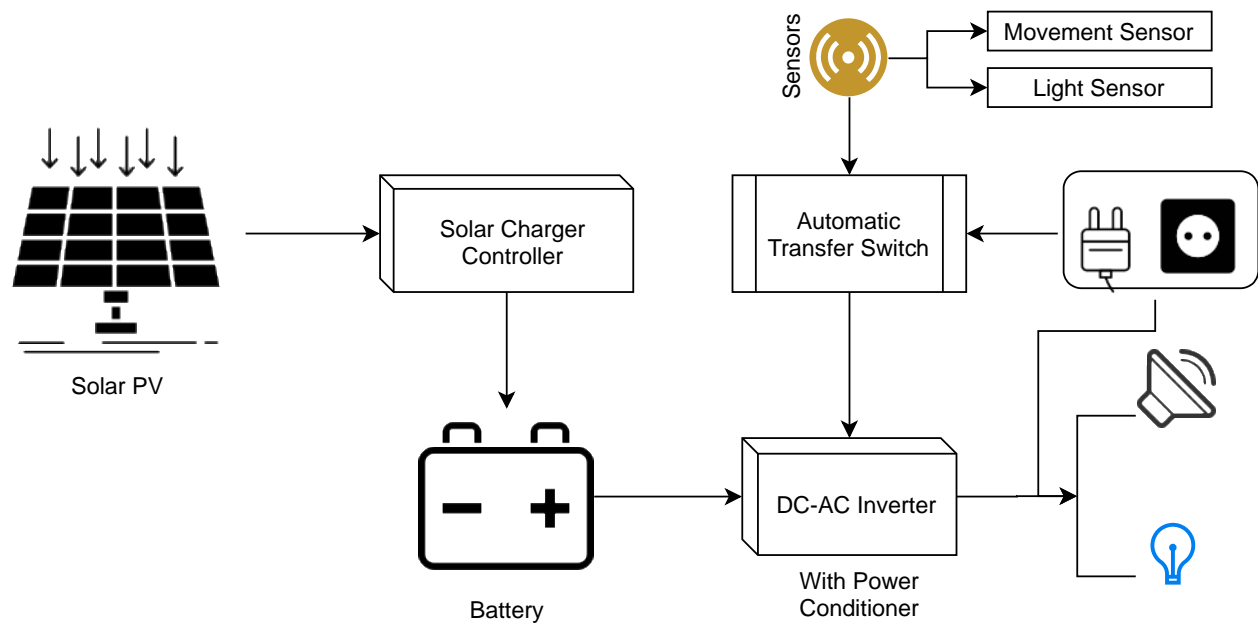

Fig. 1. The scheme of Emergency Power Supply for Mosque 
Research purpose of implementing this system is to solve the problem of power cuts during worship. The problem of power cuts can be solve, particularly for lighting and sound system. The people can continued following Imam's instruction and focus on their prayer.

The investment cost to establish the system is affordable. The operation cost is quite minimum, and the maintenance cost is very low. The solar PV may reach long lifetime and the battery may need replacement after 2 years. The prototype it is already test and work properly. This may be similarly developed and implemented in a number of mosques. The investment cost may come from the donation from Moslem people.

\section{Method}

For implementing the design as indicated in Fig. 1, some activities are design. The sequence of activities is show by the flowchart at Fig. 2. The first step to do is site survey, aimed to get the detail of the building and determine position of the system. The sunlight intensity was also be measured and the position of the panel was determined. The request to the Authority of the Mosque was also proposed.

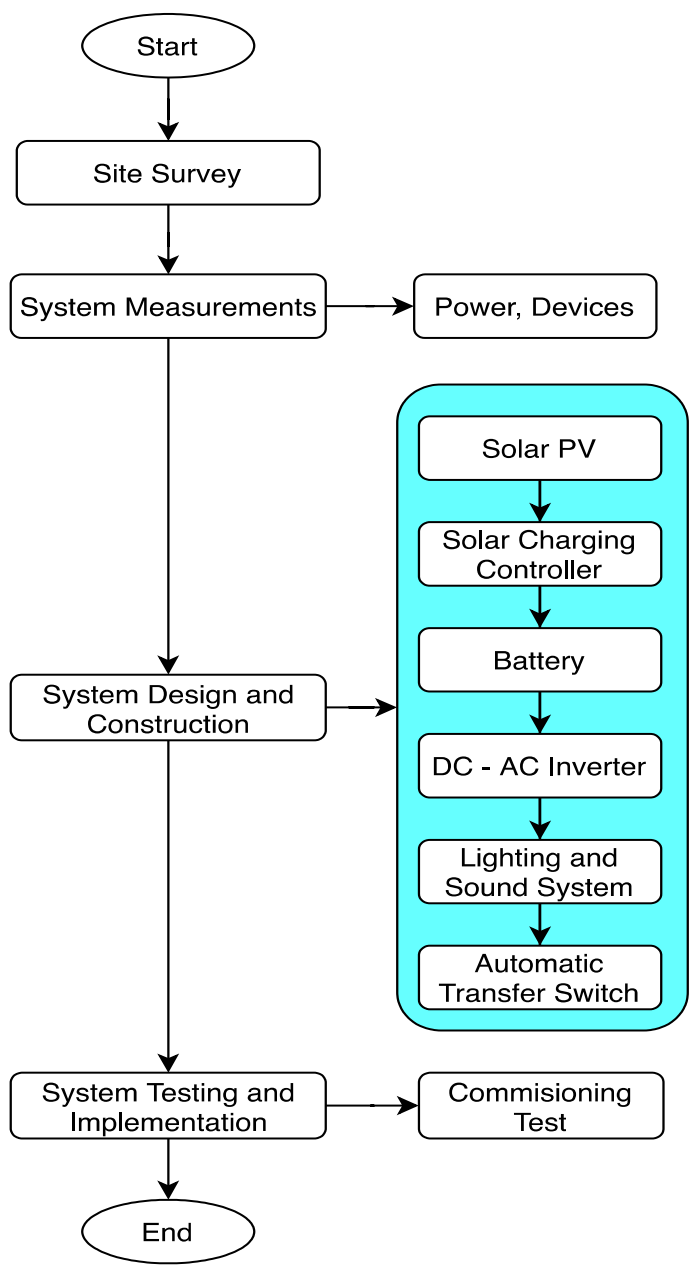

Fig. 2. Flowchart for establishing Emergency Power Supply for Mosque

From this first step, some following measurements might be carried out. These include the power capacity of electricity from the grid, the light capacity related with the space to be illuminated, the power requirement of sound system. Only two types of load that are considered in this project. As previously discussed, these loads are the vital devices that should get uninterupted power supply when the electricity went out. 
From these measurements, design of system may be determined. The capacity of solar PV is firstly determined. The power requirement of the loads necessitates about bigger capacity of solar PV. But it should be noted, that the system is designed as emergency power supply, meaning that the power will not always be required. The power is rarely used and therefore smaller solar PV is acceptable. On the other hand, the investment of this solar PV is another concern. Based on these considerations the capacity of $50 \mathrm{WP}$ was decided. This design is not only for the Mosque of Al Bakri but is expected may also be implemented on the other mosques. Therefore, this prototype should be carefully designed to have possibility to be implemented for other mosques. The $50 \mathrm{WP}$ solar PV employed in this program is shown in Fig. 3.

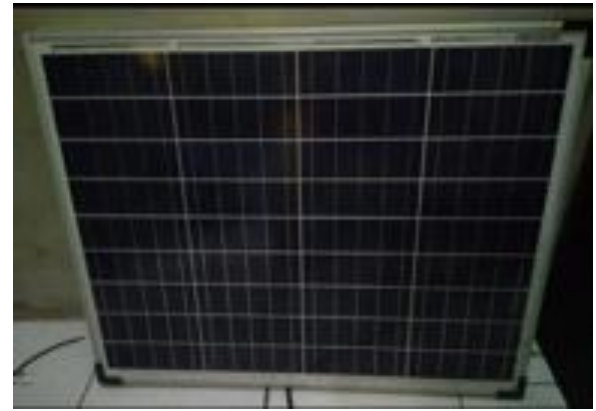

Fig. 3. Solar PV used in the project

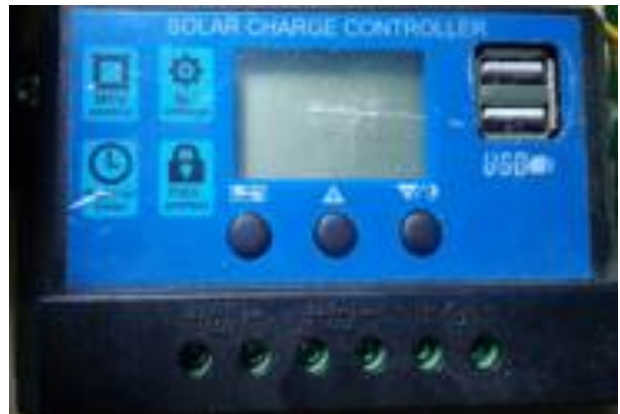

Fig. 4. Solar Charger Controller

The voltage generated by solar PV panel depends on sunlight intensity. The sunlight intensity is not constant depending on time and position, and therefore the generated voltage is also not constant [16]. On the other hand, to enable power flowing to the battery the voltage should be regulated to be at least $12 \mathrm{~V}$. For this purpose, Solar Charger Controller is employed for this assignment. The device is shown in Fig. 4.

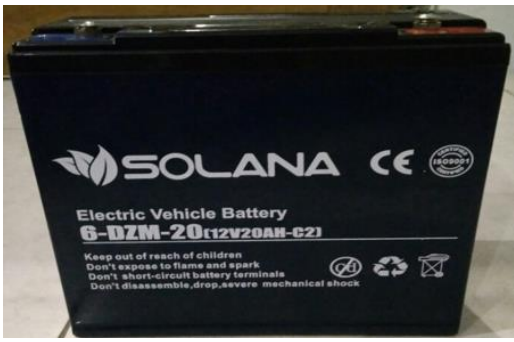

Fig. 5. Battery used in the project

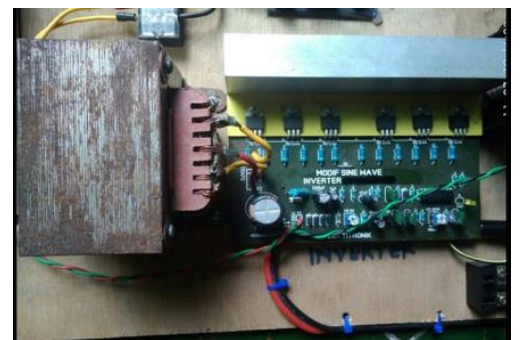

Fig. 6. DC - AC Inverter

The voltage generated by solar PV, which is regulated by Solar Charger Controller is then supplied to the battery. It is $20 \mathrm{Ah}, 12 \mathrm{~V}$ Lithium-Ion Battery as shown in Fig. 5. The power of Battery may be discharged to feed the loads through a DC-AC inverter. This device converts a DC power into AC power with specific voltage and frequency. The inverter in shown in Fig. 6.

To determine when the inverted must work, a switching mechanism is applied. This is based on whether there is a person in the mosque. A movement sensor is employed to detect if there is any person through identification of moving object. This sensor is attached at the wall of the mosque facing toward the position of person normally performing prayer. The circuit of inverter switch is shown in Fig. 7 (a) and the physical device is shown in Fig. 7 (b). This device drives the inverter to work based on the input from movement and light sensors. 
This device only instructs the inverter to operate when the electricity went out while there is a person in the mosque. If this condition happens at the night, then the light and the sound system are both energized. But, if this condition happens at the daylight, then only sound system is supplied with power.

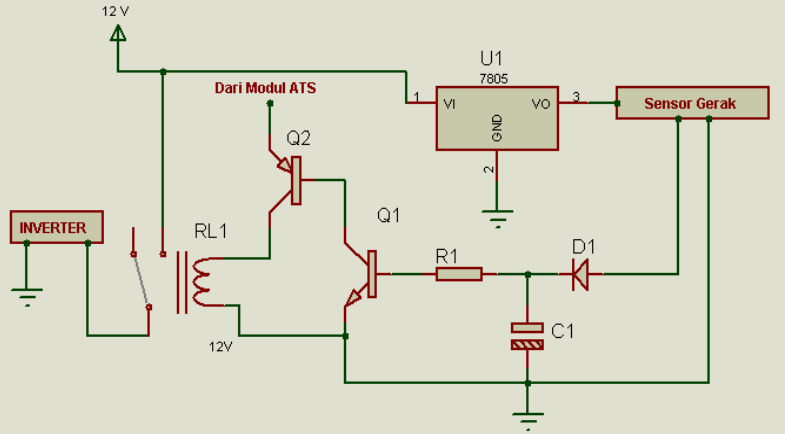

(a)

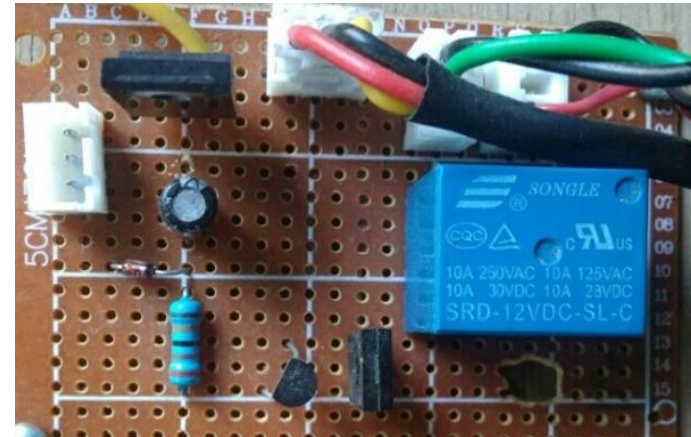

(b)

Fig. 7. Inverter Switch Modul (a) the circuit diagram (b) the hardware

The decision where the power comes from is determined by Automatic Transfer Switch (ATS). This detects power from the grid, where if it is suddenly unavailable then it changes the power source from battery. However, it should be noted that the sensors will check if there is any person in the mosque. It only permits the battery to feed the power if the prayer is taking place. Otherwise, the electricity will be left off if no prayer is performed. Once the electricity from the grid is back, the ATS will switch back the source to the grid. The circuit diagram of ATS is given in Fig. 8 (a) and the physical look is shown in Fig. 8 (b).

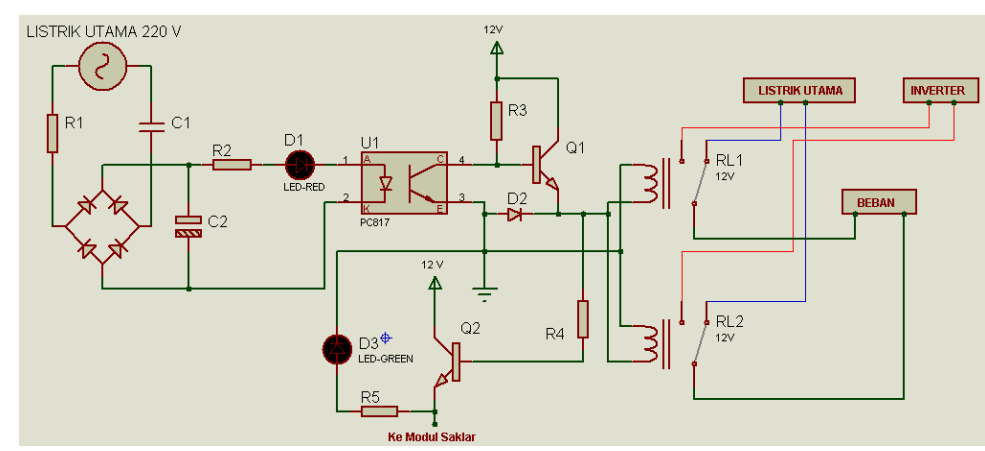

(a)

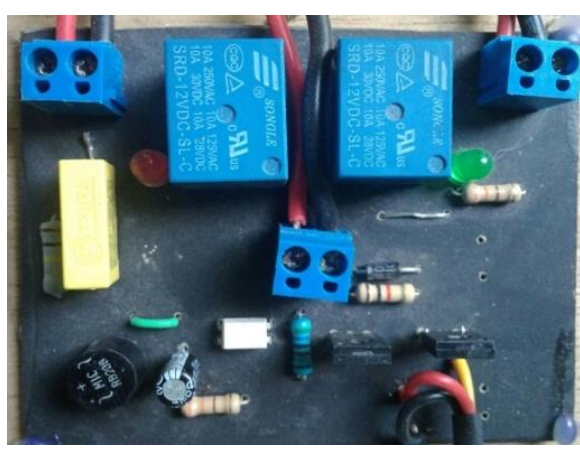

(b)

Fig 8. Automatic Transfer Switch (a) the circuit diagram (b) The hardware

The procedure on how this system works is outlined in Fig. 9. The flowchart may be described in the following scheme.

1. Automatic Transfer Switch will detect if the electricity from the grid is unavailable,

2. If there is no person in the mosque, then the system will do nothing,

3. If there is a person in the mosque detected by movement sensor, the light sensor will check the light intensity,

4. If it is at the daylight, then only sound system to be energized,

5. If it is at the nighttime, both lighting and sound system are energized,

6. When the electricity from the grid is back, then ATS will put the power source back into the grid. 


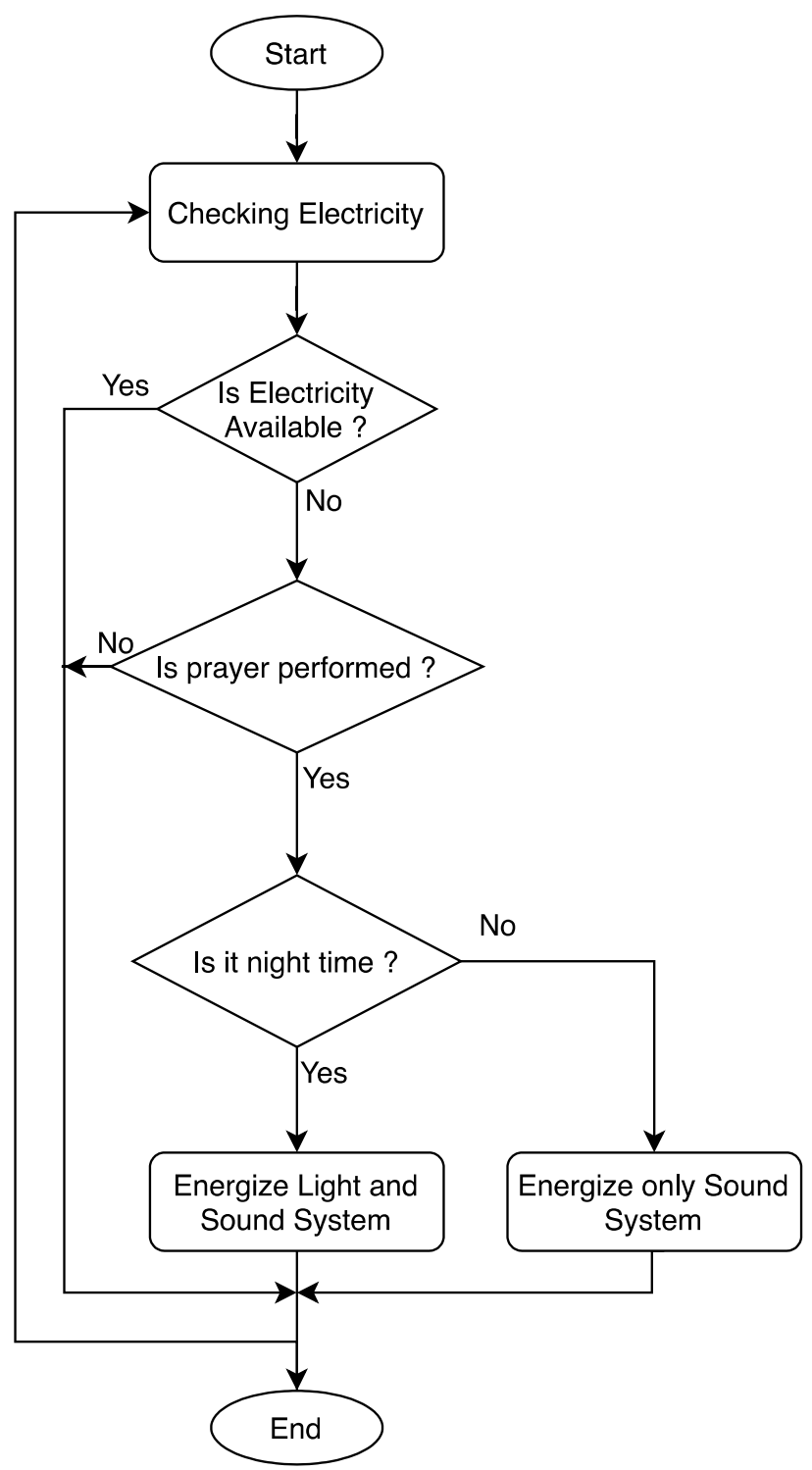

Fig. 9. Flowchart of working mechanism of emergency power supply

\section{Results and Discussion}

Based on the developed system, some measurements and testing were carried out. These include the measurement of generated voltage from solar PV panel, battery voltage, and inverter output. The measurement of inverter output was also carried out by displaying the voltage using digital oscilloscope. Some commissioning test was carried out by simulating the situation where the electricity from the grid was disconnected.

\subsection{Solar PV Measurements}

The measurement of $50 \mathrm{WP}$ solar PV panel performance was carried out using digital multimeter for the duration of $09.30-15.30$ with the interval of 1 hour each. The measurement was taken on voltage and current, while the power was mathematically calculated. The calculation of power uses eq. (1) 
$P=V \times i$

Where:

$P$ : The calculated output power of solar PV panel (Watt)

$V$ : Output voltage of solar PV panel (Volt)

$i$ : Current of solar PV panel (Amp.)

The measurement of voltage and current, and the calculated power for the solar $\mathrm{PV}$ is indicated in Table 1. It may be observed from the table that the generated voltage is sufficient to enable power charging the battery. The measured current is proportional with the voltage. The measurement results also indicate that the voltage is not constant and therefore the charging current is also not constant. In this project the concern is the use of generated power from solar PV for emergency power supply. Therefore, the focus is on the ability of solar PV providing power for emergency situation.

Table 1. The measurement results of solar PV outputs

\begin{tabular}{cccc}
\hline Time & Voltage (Volt) & Current (Amp.) & Power (Watt) \\
\hline 09.30 & 12.91 & 2.10 & 27.11 \\
10.30 & 13.21 & 2.40 & 31.70 \\
11.30 & 13.24 & 1.73 & 22.91 \\
12.30 & 13.37 & 1.59 & 21.25 \\
13.30 & 13.08 & 1.31 & 17.13 \\
14.30 & 13.21 & 1.01 & 13.34 \\
\hline
\end{tabular}

From the data of current charging, the average 16.9 Amps is obtained. For the battery capacity of $20 \mathrm{Ah}$, the charging time may be calculated using Eq. (2). considering deficiency factor of $20 \%$.

$t=\frac{C a p}{i}+20 \%\left(\frac{C a p}{i}\right)$

Where:

$t:$ The required charging time (hour)

Cap : Battery capacity (Ah)

$i$ : Current of solar PV panel (Amp.)

For the given data, the required charging time for the 20 Ah battery may be calculated as follows:

$t=\frac{20}{16.9}+20 \%\left(\frac{20}{16.9}\right)=14.2$ hours

It is long time needed to fully charge the battery. As previously discussed, capacity of the assigned solar PV is not high. There are 2 considerations behind this decision. This is an emergency power supply where the power is not always required. The time to charge is not limited in one day but could be couple of days. As long as the reserved power in battery has not been used, some additional power may still be saved in battery. It might happen that the battery is fully charged and there is no power outage, that may lead to battery discharge. If this happen then battery charging process is stopped to avoid damage. For this purpose, SCC is assigned to control this process. Another consideration in this context is since this prototype is designed for wide implementation. Different mosque may have different situation in terms of financial and physical setting. Therefore, designing minimum size of system will enable extensive application. 


\subsection{Inverter Testing}

Inverter is the device responsible to provide power with specific voltage and frequency. In this project, this device is employed to convert DC power from battery into $\mathrm{AC}$ power to supply the loads. It is somehow difficult to perfectly presents AC voltage with pure sinusoidal. This is due to inverter normally works based on switching principle. For the inverter used in this project the waveform of output voltage is not perfectly sinusoidal. It just complies that the voltage type is Alternating Current (AC) in term of the polarity of voltage changes for every half period.

The voltage waveform presented by the inverter is shown in Fig. 10 (b). Compared with the sinusoidal voltage at Fig. 10 (a) from electricity grid, the output voltage of the inverter is lower in term of quality. However, the voltage and the frequency are maintained to meet the load requirements. On the other hand, since the power is simply used for (very) short time, the non-sinusoidal voltage may still be used to energize the loads without any prominent impact.

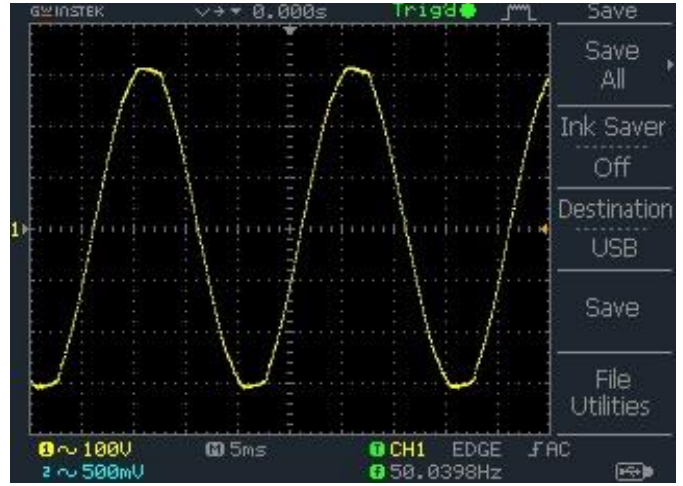

(a)

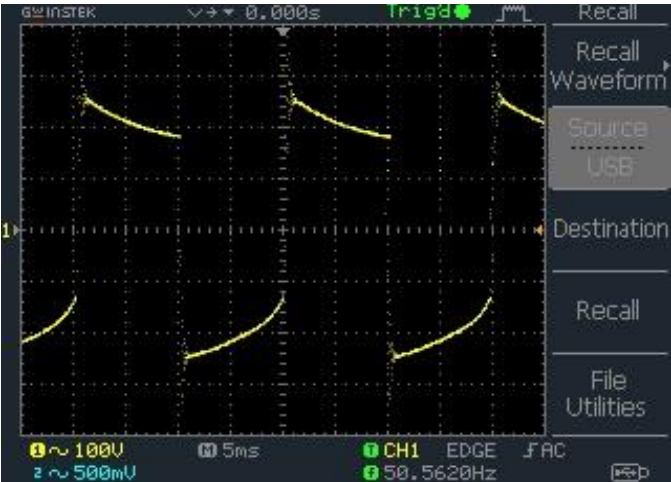

(b)

Fig. 10. The sinusoidal waveform of: (a) electricity grid, and (b) inverter output

The inverter is further tested on its capacity in supplying the load. The tests were carried out by supplying the lighting and sound system. The tests were distinguished for daylight and nighttime. The results are displayed in Table 2 indicating voltage reduction because the inverter providing some loads. It may also be noted that the unloaded inverter still draws the current from battery since it is used to compensate some losses.

Table 2. Measurement results of inverter

\begin{tabular}{lccc}
\hline Load Type & Current (Amp.) & Voltage (Volt) & Power (Watt) \\
\hline \multicolumn{4}{c}{ Daylight } \\
Unloaded Inverter & 0.8 & 12.5 & 10 \\
Amplifier & 4.5 & 12.3 & 55.35 \\
\hline \multicolumn{4}{c}{ Nighttime } \\
Unloaded Inverter & 0.8 & 12.5 & 10 \\
Amplifier & 4.5 & 12.3 & 55.35 \\
2 x 6W LED Light & 0.98 & 12.3 & 12.05 \\
\hline
\end{tabular}

The Table indicates that the dominant power consumption is on Amplifier. For the nighttime additional load of $2 \times 6 \mathrm{~W}$ LED light should also be taken into account. The application of load implies reduction of battery voltage. 
However, the minimum battery voltage is still acceptable. For the long operation of emergency power supply, the bad voltage reduction may happen.

Considering the battery deficiency of $20 \%$ the battery may withstand for the duration of use that may be calculated using Eq. (4).

$t=\frac{C a p}{i}-\left(20 \% x \frac{C a p}{i}\right)$

Where $t$ is maximum duration of battery use. For the capacity of $20 \mathrm{Ah}$, the battery may provide the power at daylight as:

$t=\frac{20}{0.8+4.5}-\left(20 \% x \frac{20}{0.8+4.5}\right)=3$ hours

However, at nighttime, the service duration is slightly lower due to additional load of $2 \mathrm{x}$ $6 \mathrm{~W}$ lighting. This may be calculated as:

$t=\frac{20}{0.8+4.5+0.98}-\left(20 \% x \frac{20}{0.8+4.5+0.98}\right)=2.56$ hours

For once prayer, the length of activity is about 20 minutes. Therefore, the capacity of battery providing power during electricity shutdown is very enough. Mentioning that movement sensor will deactivate the supply when no person is detected, the battery will discontinue supplying the loads when people is no longer in the mosque. Since, it may be concluded that the prayer has finished. While the electricity is still off, if the prayer is complete and no more person in the mosque then the power supply from battery will be stopped.

\subsection{Sensor Testing}

The performance of devices greatly depends on the accuracy of sensors. In order to assess the sensors' accuracy, some commissioning tests were performed. It was carried out on June 30, 2019 at the Mosque of Al Bakri. Table 3 indicates the assessment results of sensor performance. It may be observed that when the electricity is 'on' then either sensor detects person or not, the modules of ATS and Inverter are 'off'. This means that emergency power supply does nothing if the electricity from the grid is available. When the electricity is 'off' then ATS module is 'on'. This switches the power into inverter. But it should wait the sensor checking the present of people in the mosque. If some person is detected to be in the mosque, then the inverter is instructed to be 'on' and take DC power from battery and convert it into AC power for supplying the lighting and sound system.

Table 3. Device performance assessment results

\begin{tabular}{lcc}
\hline Sensor Status & ATS Module & Inverter Module \\
& Electricity ON & \\
\hline No person detected & OFF & OFF \\
Person detected & OFF & OFF \\
\hline & Electricity OFF & \\
\hline No person detected & ON & OFF \\
Person detected & ON & ON \\
\hline
\end{tabular}




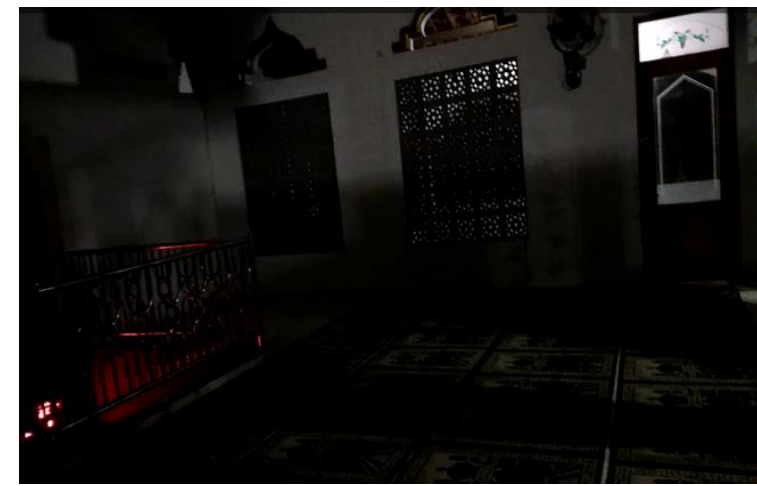

(a)

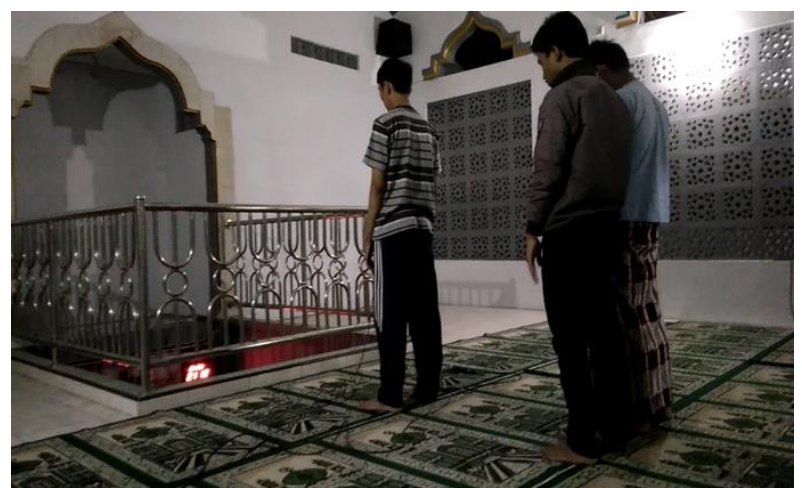

(b)

Fig. 11. The response of emergency power supply: (a) no person, (b) persons detected

A real test for the system was taken by emulating the electricity shut down. Fig. 11 demonstrates situation when the electricity is suddenly 'unavailable'. When no person was detected in the mosque, then the inverter stays 'off'. However, when some persons came to the mosque and performed prayer, then the sensor detected them. The emergency power supply was immediately 'on' and supplied the loads (lighting and sound system). The test indicates that the system works properly.

\section{Conclusion}

A scheme of emergency power supply for a mosque is proposed and a design is developed. In conclusion the prayer may continue even the electricity went out. The design has been implemented and works properly. The system consists of solar PV as a power generator from which the voltage is regulated by Solar Charger Controller. The customized voltage enables power flowing to a battery for charging process. An inverter is assigned to convert DC power of battery becoming AC power required by lighting and sound system. However, this conversion may only take place when the prayer is going on. Some sensors are employed to check the conditions of mosque leading to decision if the loads should be energized and which load should be powered.

Automatic Transfer Switch is responsible to change the electricity source from grid or battery. Some assessments have been carried out indicating the system may work properly. Commissioning test has also been done demonstrating the system has a good performance.

This system assists the vital devices of mosque, which should continue operating while the electricity went out. This supports the prayer to keep going on with the devices supplied from battery. This system needs to be further developed considering the best size, proper installation, and wide application in different location. 


\section{References}

[1] P. Stenzel, T. Kannengießer, L. Kotzur, P. Markewitz, M. Robinius, and D. Stolten, "Emergency power supply from photovoltaic battery systems in private households in case of a blackout - A scenario analysis," Energy Procedia, vol. 155, pp. 165-178, Nov. 2018, doi: 10.1016/j.egypro.2018.11.058.

[2] N. A. Czarnecki, "Transfer switch for automatically switching between alternative energy source and utility grid," US9583942B2, Feb. 28, 2017.

[3] I.-D. Deaconu, M. Stănculescu, A.-I. Chirilă, V. Năvrăpescu, and H. Andrei, "On Automatic Transfer Switch System Security," in 2018 International Conference on Applied and Theoretical Electricity (ICATE), Oct. 2018, pp. 1-6, doi: 10.1109/ICATE.2018.8551369.

[4] M. LokeshReddy, P. J. R. P. Kumar, S. A. M. Chandra, T. S. Babu, and N. Rajasekar, "Comparative study on charge controller techniques for solar PV system," Energy Procedia, vol. 117, pp. 1070-1077, Jun. 2017, doi: 10.1016/j.egypro.2017.05.230.

[5] K. Indrakoesoema, K. Handono, E. Sumarno, Kiswanta, and A. Sudirman, "Emergency Power Supply of Control Rod for RDE," J. Phys.: Conf. Ser., vol. 1198, no. 5, p. 052005, Apr. 2019, doi: 10.1088/1742-6596/1198/5/052005.

[6] H. Islam et al., "Performance evaluation of maximum power point tracking approaches and photovoltaic systems," Energies, vol. 11, no. 2, Feb. 2018, doi: 10.3390/en11020365.

[7] A. Bhattacharjee, H. Samanta, N. Banerjee, and H. Saha, "Development and validation of a real time flow control integrated MPPT charger for solar PV applications of vanadium redox flow battery," Energy Conversion and Management, vol. 171, pp. 1449-1462, Sep. 2018, doi: 10.1016/j.enconman.2018.06.088.

[8] D. Ouyang, Y. He, M. Chen, J. Liu, and J. Wang, "Experimental study on the thermal behaviors of lithium-ion batteries under discharge and overcharge conditions," $J$ Therm Anal Calorim, vol. 132, no. 1, pp. 65-75, Apr. 2018, doi: 10.1007/s10973-0176888-x.

[9] Y. Fernandes, A. Bry, and S. de Persis, "Identification and quantification of gases emitted during abuse tests by overcharge of a commercial Li-ion battery," Journal of Power Sources, vol. 389, pp. 106-119, Jun. 2018, doi: 10.1016/j.jpowsour.2018.03.034.

[10] K. Zeb et al., "A comprehensive review on inverter topologies and control strategies for grid connected photovoltaic system," Renewable and Sustainable Energy Reviews, vol. 94, pp. 1120-1141, Oct. 2018, doi: 10.1016/j.rser.2018.06.053.

[11] E. Hernández-Márquez, R. Silva-Ortigoza, J. R. García-Sánchez, M. MarcelinoAranda, and G. Saldaña-González, "A DC/DC Buck-Boost Converter-Inverter-DC Motor System: Sensorless Passivity-Based Control,” IEEE Access, vol. 6, pp. 3148631492, 2018, doi: 10.1109/ACCESS.2018.2846614.

[12] L. H. Fang, R. B. Abd Rahim, M. Isa, S. I. Syed Hassan, and B. B. Ismail, “The Design of Operational Amplifier for Low Voltage and Low Current Sound Energy Harvesting System,” IOP Conf. Ser.: Mater. Sci. Eng., vol. 318, p. 012035, Mar. 2018, doi: 10.1088/1757-899X/318/1/012035.

[13] A. Arshad, M. Rizwan, and A. Maqsood, "Design \& Implementation of Cost Effective Automatic Transfer Switch,” vol. 4, no. 5, p. 10, 2016. 
[14] Y. Shi, B. Xu, Y. Tan, D. Kirschen, and B. Zhang, "Optimal Battery Control Under Cycle Aging Mechanisms in Pay for Performance Settings," IEEE Transactions on Automatic Control, vol. 64, no. 6, pp. 2324-2339, Jun. 2019, doi: 10.1109/TAC.2018.2867507.

[15] Q. Kellner, E. Hosseinzadeh, G. Chouchelamane, W. D. Widanage, and J. Marco, "Battery cycle life test development for high-performance electric vehicle applications," Journal of Energy Storage, vol. 15, pp. 228-244, Feb. 2018, doi: 10.1016/j.est.2017.11.019.

[16] P. Chaudhary and M. Rizwan, "Voltage regulation mitigation techniques in distribution system with high PV penetration: A review," Renewable and Sustainable Energy Reviews, vol. 82, pp. 3279-3287, Feb. 2018, doi: 10.1016/j.rser.2017.10.017. 